\title{
Effects of nitroglycerin versus labetalol on peripheral perfusion during deliberate hypotension for sinus endoscopic surgery: a randomized, controlled, double-blinded trial
}

\author{
Marwa Zayed ${ }^{1,2 *}$, Heba Nassar ${ }^{1}$, Ahmed Hasanin ${ }^{1}$, Amany H. Saleh', Passaint Hassan', Dalia Saad²,
} Sahar Mahmoud ${ }^{2}$, Ghada Abo Bakr ${ }^{2}$, Eman Fouad ${ }^{1}$, Norhan Saleh ${ }^{2}$, Maha Ismail ${ }^{1}$ and Hani El-Hadi ${ }^{2}$

\begin{abstract}
Background: Deliberate hypotension is used to provide a bloodless field during functional endoscopic sinus surgery; however, the impact of controlled hypotension during anesthesia on peripheral tissue perfusion has not been extensively evaluated. The aim of this study was to compare the impact of nitroglycerin- versus labetalolinduced hypotension on peripheral perfusion.

Methods: The present randomized, double-blinded, controlled trial included adult patients undergoing endoscopic sinus surgery. Patients were allocated to one of two groups according to the drug received for induction of deliberate hypotension: nitroglycerin $(n=20)$ or labetalol $(n=20)$. Mean arterial pressure was maintained at 55-65 $\mathrm{mmHg}$ in both groups. Both study groups were compared according to pulse oximeter-derived peripheral perfusion index (primary outcome), serum lactate level, mean arterial pressure, heart rate, surgical field score, and intraoperative blood loss.

Results: Forty patients were included in the final analysis. The nitroglycerin group exhibited a higher peripheral perfusion index at nearly all records $(p<0.0001)$ and lower postoperative serum lactate levels $(1.3 \pm 0.2 \mathrm{mmol} / \mathrm{L} \mathrm{vs}$. $1.7 \pm 0.4 \mathrm{mmol} / \mathrm{L} ; p=0.001$ ) than the labetalol group. The peripheral perfusion index was higher in the nitroglycerin group than at baseline at most intraoperative readings. The median surgical field score was modestly lower in the labetalol group than in the nitroglycerin group in the first 20 min (2 [interquartile range (IQR) 2-2.5] versus 1.5 [IQR $1-2$ ]; $p=0.001$ ). Both groups demonstrated comparable and acceptable surgical field scores in all subsequent readings.
\end{abstract}

Conclusion: Nitroglycerin-induced deliberate hypotension was accompanied by higher peripheral perfusion index and lower serum lactate levels than labetalol-induced deliberate hypotension during sinus endoscopic surgery. (Continued on next page)

\footnotetext{
* Correspondence: marwa.zayed@kasralainy.edu.eg

'Department of Anesthesia and Critical Care Medicine, Cairo University, Cairo, Egypt

${ }^{2}$ Department of Anesthesia and Critical Care Medicine, Faculty of Medicine, Cairo University, 01 elsarayah street, Elmanyal, Cairo 11559, Egypt
}

C C The Author(s). 2020 Open Access This article is licensed under a Creative Commons Attribution 4.0 International License, which permits use, sharing, adaptation, distribution and reproduction in any medium or format, as long as you give appropriate credit to the original author(s) and the source, provide a link to the Creative Commons licence, and indicate if changes were made. The images or other third party material in this article are included in the article's Creative Commons licence, unless indicated otherwise in a credit line to the material. If material is not included in the article's Creative Commons licence and your intended use is not permitted by statutory regulation or exceeds the permitted use, you will need to obtain permission directly from the copyright holder. To view a copy of this licence, visit http://creativecommons.org/licenses/by/4.0/. The Creative Commons Public Domain Dedication waiver (http://creativecommons.org/publicdomain/zero/1.0/) applies to the data made available in this article, unless otherwise stated in a credit line to the data. 
(Continued from previous page)

Trial registration: The study was registered at clinicaltrials registry system with trial number: NCT03809065. Registered at 19 January 2019. This study adheres to CONSORT guidelines.

Keywords: Deliberate hypotension, Nitroglycerin, Labetalol, Peripheral perfusion, Lactate

\section{Background}

Controlled hypotension is commonly used during functional endoscopic sinus surgery (FESS) to ensure a bloodless operative field. The main risk in controlled hypotension is impaired peripheral perfusion and subsequent ischemia of vital organs [1,2]. A target mean arterial pressure (MAP) of $50-65 \mathrm{mmHg}$ has been considered sufficient to achieve acceptable surgical conditions [1]. However, the use of blood pressure as the only hemodynamic target is not sufficient to ensure proper oxygen delivery to different organs, which is the main goal of cardiac output. Because monitoring of vital organ perfusion requires either sophisticated or invasive equipment, the use of deliberate hypotension has been limited by the fear of unmonitored ischemia of vital organs. Monitoring of blood flow in non-vital organs (such as the skin) has been considered to be a good alternative for assessment of the impact of deliberate hypotension on tissue perfusion. Peripheral perfusion of non-vital organs is usually impaired earlier than vital organs [3]; therefore, evaluation of perfusion of non-vital organs is considered to be an adequate measure of patient safety during anesthesia [4]. Furthermore, the development of simple non-invasive measures, such as pulse oximetryderived peripheral perfusion index (PPI), has provided effective and easy measures for tissue perfusion [3]. Recently, PPI has been reported to be a useful hemodynamic measure during anesthesia [4]. Thus, we hypothesized that monitoring PPI would be a useful tool for evaluating the safety of deliberate hypotension. Serum lactate is another frequently used marker of global tissue perfusion in the operating room as well as the intensive care unit [3].

Nitroglycerin and labetalol are commonly used drugs for controlled hypotension during anesthesia. Both drugs are also used for acute management of emergent hypertension in emergency departments. Nitroglycerin is a direct vasodilator and its main action is through venodilation. Labetalol combines an $\alpha 1$ blocking effect and beta-adrenergic blocking activity to reduce systemic vascular resistance, with little effect on cardiac output $[5,6]$. Both drugs were previously compared during controlled hypotension with regard to surgical field quality and blood loss [6-9]. To date, however, no study has compared the effects of both drugs on peripheral perfusion.

The aim of this study, therefore, was to compare the impact of nitroglycerin and labetalol on peripheral perfusion when used for induction of deliberate hypotension during
FESS. We evaluated peripheral perfusion using PPI and serum lactate levels as markers of peripheral and global tissue perfusion.

\section{Methods}

This randomized, double-blinded, parallel study was conducted at Cairo University Hospital (Cairo, Egypt) after receiving approval (N-53-2016) from the Research Ethics Committee, Faculty of Medicine, Cairo University. Written informed consent was obtained from all participants before enrollment.

Forty adult patients $18-45$ years of age, with American Society of Anesthesiologists physical status I-II and scheduled for FESS, were included. Individuals with uncontrolled hypertension, cerebrovascular disorders, coagulation disorders, cardiovascular diseases, renal impairment, liver impairment, and history of allergic reaction to any of the study medications were excluded from the study.

An online randomization program (http://www.randomizer.org) was used by a research assistant to generate random sequences. Each code was enclosed in a sealed opaque envelope. Another research assistant, who was not involved in outcome assessment, was responsible for opening the envelope and preparing the study drug. Patients were allocated before induction of anesthesia into either the nitroglycerin $(n=20)$ or labetalol $(n=20)$ group. The patient, attending anesthesiologist, and surgeon were blinded to the study group allocation.

\section{Anesthetic management}

On arrival to the operating room, intravenous midazolam $(0.05 \mathrm{mg} / \mathrm{kg})$ and fentanyl $(50 \mu \mathrm{g})$ were administered as premedication to all participants. Two 18-gauge peripheral intravenous catheters were secured: one for fluid administration; and the other for infusion of the study drug. Monitoring included electrocardiography, noninvasive arterial blood pressure, end-tidal carbon dioxide $\left(\mathrm{CO}_{2}\right)$, and temperature probe. PPI was measured using a pulse oximetry probe (Masimo Radical 7; Masimo Corp., Irvine, CA, USA), which was attached to the patients' index finger of the non-dominant hand. Invasive blood pressure was monitored using a 20-gauge radial artery catheter connected to a pressure transducer. Arterial blood gases were measured using a specialized, commercially available device (GEM Premier 3000, Bedford, MA, USA). 
Anesthesia was induced using fentanyl $(2 \mu \mathrm{g} / \mathrm{kg})$, propofol $(1.5-2 \mathrm{mg} / \mathrm{kg})$, atracurium $(0.5 \mathrm{mg} / \mathrm{kg})$ to facilitate insertion of an appropriately sized endotracheal tube, and $1 \mathrm{~g}$ paracetamol for analgesia. Anesthesia was maintained using an isoflurane end-tidal concentration of $1.2 \%$ and $0.01 \mathrm{mg} / \mathrm{kg}$ atracurium every $20 \mathrm{~min}$. Lactated Ringer's solution was infused at a rate of $5 \mathrm{~mL} / \mathrm{kg}$. Mechanical ventilation was adjusted to maintain endtidal $\mathrm{CO}_{2}$ at $30-35 \mathrm{mmHg}$. The head-up position was maintained at $30^{\circ}$, and nasal mucosa was infiltrated by the surgeon with $2 \mathrm{~mL}$ of $2 \%$ lignocaine with epinephrine at 1:100,000 dilution.

\section{Drug preparation and hemodynamic management}

Nitroglycerin (Nitronal ${ }^{\circ}$ glyceryl trinitrate, $1 \mathrm{mg} / \mathrm{mL}$, G. Pohl-Boskamp GmbH \& Co. KG, 25551 Hohenlockstedt, Germany) was diluted by adding $3 \mathrm{~mL}(3 \mathrm{mg})$ to $47 \mathrm{~mL}$ of $0.9 \%$ saline in a $50 \mathrm{~mL}$ syringe. Labetalol (Labetalol Hydrochloride Injection ${ }^{\circ}, 5 \mathrm{mg} / \mathrm{ml}$ ) was diluted by adding $10 \mathrm{~mL}$ (50 mg) to $40 \mathrm{~mL}$ of $0.9 \%$ saline in a $50 \mathrm{~mL}$ syringe. Both drugs were infused after endotracheal intubation with a starting dose of $0.5 \mathrm{~mL} / \mathrm{kg} / \mathrm{h}$ to have a starting dose of $0.5 \mu \mathrm{g} / \mathrm{kg} / \mathrm{min}$ for nitroglycerin and $0.5 \mathrm{mg} / \mathrm{kg} / \mathrm{h}$ for labetalol. The infusion was then titrated according to patient response. The rate of nitroglycerin infusion was $0.5-2 \mu \mathrm{g} / \mathrm{kg} / \mathrm{min}$, whereas the labetalol infusion rate was $0.5-2 \mathrm{mg} / \mathrm{kg} / \mathrm{h}$.

The infusion rate was finely adjusted to maintain invasive MAP at approximately $55-65 \mathrm{mmHg}$ or until achieving the adequate surgical field (defined as surgical field score $[\mathrm{SFS}]<3$ ). Hypotension was defined as a decrease in MAP below the target level, which was managed by decreasing the rate of drug infusion by $50 \%$ up to transient holding of infusion. If hypotension persisted after stopping drug infusion, incremental doses of intravenous ephedrine $(5 \mathrm{mg})$ were planned to be administered. Bradycardia was defined as a heart rate $<50$ beats/ min and was planned to be treated with intravenous atropine $0.5-1.0 \mathrm{mg}$ and discontinuation of the infused drug.

The surgical field was evaluated according to SFS [10] by a surgeon, who was blinded to the study groups, and scored from 0 to 5 as follows: 0 , no bleeding; 1 slight bleeding (no suctioning of blood required); 2, slight bleeding (occasional suctioning required, surgical field not threatened); 3 slight bleeding (frequent suctioning required, bleeding threatened surgical field a few seconds after suction was removed); 4, moderate bleeding (frequent suctioning required, bleeding threatened the surgical field directly after suction was removed; and 5 , severe bleeding (constant suctioning required, bleeding appears faster and can be removed by suction, surgical field severely threatened and surgery not possible).
Twenty minutes before the end of the procedure, the infused drugs were gradually weaned off. At the conclusion of surgery, isoflurane was discontinued, and residual neuromuscular blockade was reversed using neostigmine $0.05 \mathrm{mg} / \mathrm{kg}$ and atropine $0.02 \mathrm{mg} / \mathrm{kg}$.

\section{Outcomes \\ Primary outcome}

PPI was measured at the following time points: before induction of anesthesia; $1 \mathrm{~min}$ after endotracheal intubation; every $5 \mathrm{~min}$ after initiation of study drug infusion until the end of the procedure; and every $10 \mathrm{~min}$ in the post-anesthesia care unit for $60 \mathrm{~min}$. During data analysis, measurements were averaged every $15 \mathrm{~min}$ until the end of the operation; the postoperative $60 \mathrm{~min}$ was averaged in one point.

\section{Secondary outcomes}

Serum lactate concentration: Two samples were obtained at baseline and $60 \mathrm{~min}$ after extubation. Total intraoperative blood loss was measured from the suction device and gauze that was used to dry the surgical field. SFS was measured every 5 min intraoperatively until the end of the procedure. Each two successive measurements were averaged (every $10 \mathrm{~min}$ ) during analysis.

Mean arterial blood pressure and heart rate were assessed at the following time points: pre-induction, 1 min after endotracheal intubation (intubation was performed 2 min after induction of anesthesia); every $5 \mathrm{~min}$ after initiation of study drug infusion until the end of the procedure, and every $10 \mathrm{~min}$ in the post-anesthesia care unit for $60 \mathrm{~min}$. During data analysis, intraoperative measurements were averaged every $15 \mathrm{~min}$; the postoperative $60 \mathrm{~min}$ was averaged in one point.

\section{Statistical analysis}

In a pilot study involving 5 patients, an intraoperative, average PPI was reported during the first $1 \mathrm{~h}$ of anesthesia after nitroglycerin infusion at a mean ratio of $4.5 \pm 0.8$ during the same operation. A sample size that could detect $20 \%$ difference in PPI (i.e., 0.9) between the two study groups was calculated using MedCalc software version 14.10.2 (MedCalc Software bvba, Ostend, Belgium). A minimum of 34 patients (17 patients per group) was calculated to have a study power of $80 \%$ and an alpha error of 0.05 . The number was increased to 40 patients (20 patients per group) to compensate for possible/projected dropouts. We chose $20 \%$ mean difference in the PPI during sample size calculation because this relative change was previously reported as an accurate index for increased cardiac output after passive leg raising [11].

SPSS version 15 (IBM Corporation, Chicago, IL, USA) for Windows (Microsoft Corporation, Redmond, WA, USA) was used for data analysis. Categorical data are 
expressed as frequency (percentage [\%]) and analyzed using the chi-squared test. Normality of continuous data was verified using the Shapiro-Wilk test, which are expressed as mean \pm standard deviation (SD) or median (interquartile range [IQR]), as appropriate. Continuous data were analyzed using the unpaired $t$ test or the Mann-Whitney test as appropriate. Repeated measures were analyzed using analysis of variance (ANOVA) for repeated measures with post-hoc pairwise comparisons using the Bonferroni test. Differences with $P<0.05$ were considered to be statistically significant.

\section{Results}

Forty-five patients, recruited from January to May 2019, were screened for eligibility in this study. Two patients did not meet the inclusion criteria, three declined to participate, and 40 were randomly assigned to receive one of the two interventions. All patients completed the intervention and data were available for final analysis (Fig. 1). Patient characteristics and operative data were comparable between the study groups; with the exception of time to reach target SFS, which was lower in the labetalol group (Table 1). The mean nitroglycerin infusion rate and total infused dose were $1.7 \pm 0.3 \mu \mathrm{g} / \mathrm{kg} / \mathrm{min}$ and $13.9 \pm 3.5 \mathrm{mg}$, respectively. Furthermore, the mean labetalol infusion rate and total infused dose were $0.8 \pm 0.2 \mathrm{mg} /$ $\mathrm{kg} / \mathrm{h}$ and $98.7 \pm 19.7 \mathrm{mg}$, respectively. No patient in either group required doses of rescue atropine or ephedrine.

Mean arterial pressure was comparable between the study groups at most of the time points (Fig. 2). Heart rate was lower in the labetalol group compared to the nitroglycerin group starting from 90 min until $135 \mathrm{~min}$ after induction of anesthesia (Fig. 3). The PPI was higher in the nitroglycerin group than in the labetalol group at nearly all records (Fig. 4). Postoperative serum lactate levels were modestly lower in the nitroglycerin group than in the labetalol group (Table 1).

SFS was modestly lower in the first 20 min after drug infusion in the labetalol group compared with the nitroglycerin group. Subsequent SFS values in both groups were acceptable $(<3)$ until the conclusion of surgery

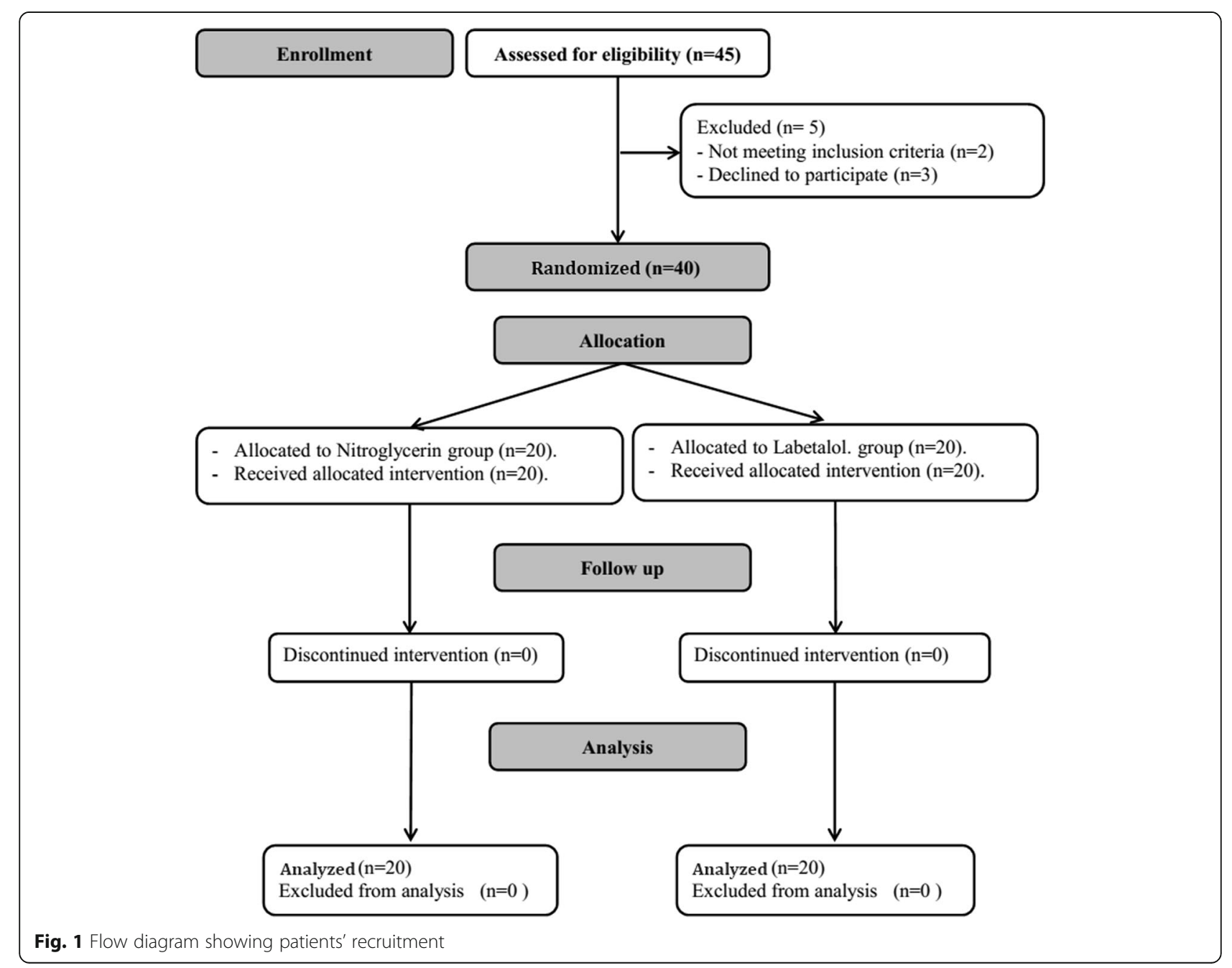


Table 1 Demographic and surgical data

\begin{tabular}{llll}
\hline Data & Nitroglycerin group $(n=20)$ & Labetalol group $(n=20)$ & $P$ value \\
\hline Age (years) & $30.1 \pm 4.8$ & $30.6 \pm 5.7$ & 0.791 \\
Weight(Kg) & $76.9 \pm 9.4$ & $77.3 \pm 8.2$ & 0.901 \\
Gender(M/F) & $12 / 8$ & $11 / 9$ & 0.749 \\
ASA $(I / I)$ & $15 / 5$ & $16 / 4$ & 0.704 \\
Duration of anesthesia (min) & $140 \pm 20.3$ & $143.7 \pm 15.9$ & 0.520 \\
Duration of controlled hypotension $(\mathrm{min})$ & $101.5 \pm 10.8$ & $104.2 \pm 8.7$ & 0.401 \\
Time to reach target SFS (min) & $11(10-20)$ & $5(5-15)^{*}$ & 0.010 \\
Total fentanyl consumption $(\mu \mathrm{g})$ & $227.5 \pm 25.5$ & $215 \pm 22.1$ & 0.105 \\
\hline
\end{tabular}

Data are presented as mean $\pm S D$, frequency, or median (interquartile range). ${ }^{*}$ Denotes significance compared with nitroglycerin group; $P<0.05$. Data were analyzed using the chi-squared test, the unpaired t test and the Mann-Whitney test as appropriate

(Table 2). Intraoperative blood loss was comparable in both groups (Table 1).

\section{Discussion}

Results of our study revealed that nitroglycerin-induced deliberate hypotension was associated with more preserved PPI compared with labetalol-induced deliberate hypotension. Both study drugs provided acceptable surgical conditions; however, nitroglycerin infusion appeared to be safer in terms of peripheral tissue perfusion. We also found that using nitroglycerin for induction of controlled hypotension did not impair peripheral tissue perfusion.

There are two possible mechanisms that may account for the superiority of peripheral perfusion in nitroglycerin compared to labetalol. 1. Administration of vasodilator drugs improves microcirculatory blood flow by increasing precapillary inflow pressure $[12,13] .2$. Nitroglycerin is a vasodilator with specific effects on peripheral perfusion dynamics. It acts on the venous capacitance vessels, resulting in a decrease in venular outflow pressure, with further increase in pressure gradient in the microvascular bed. This may favor an increase in microvascular blood flow

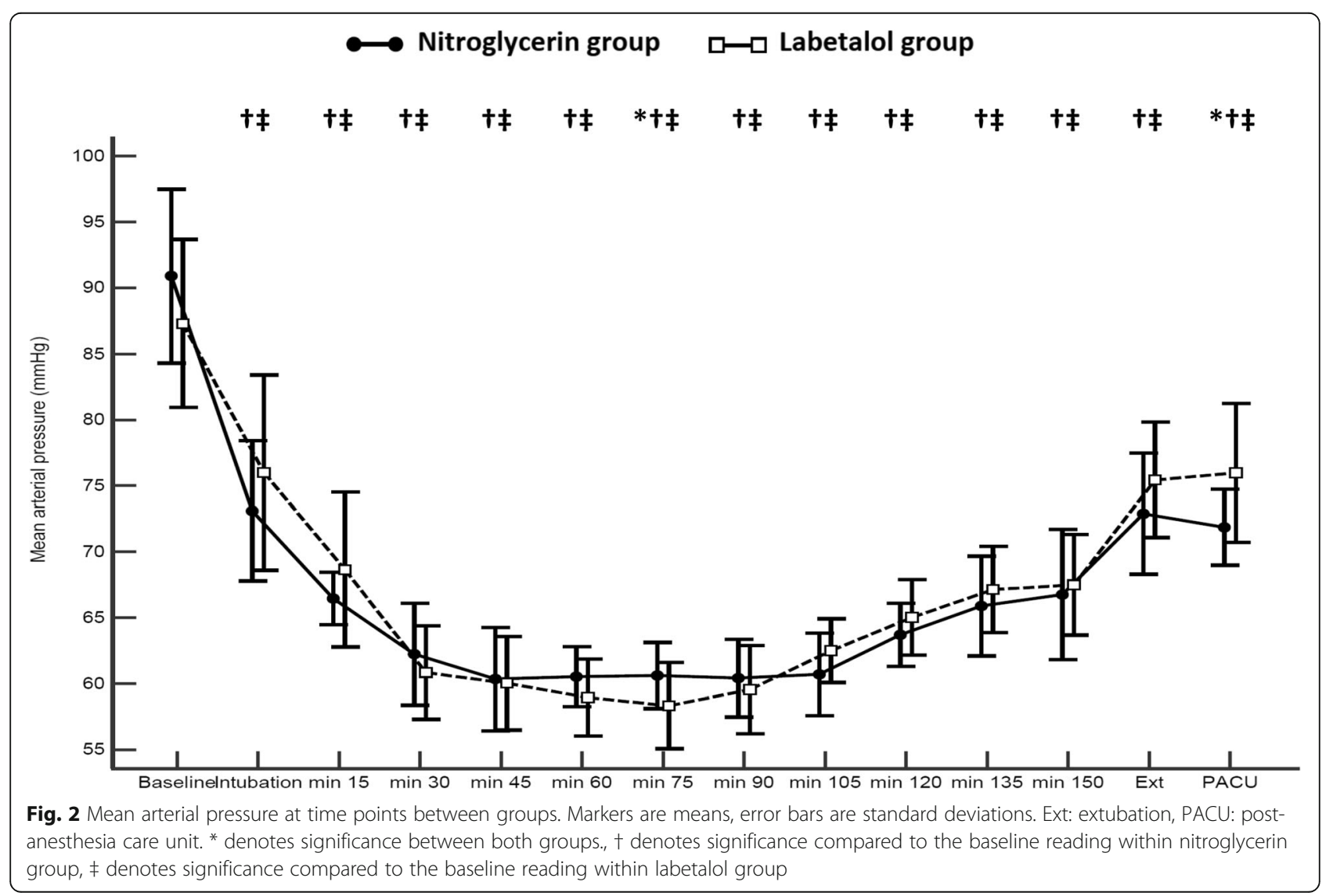




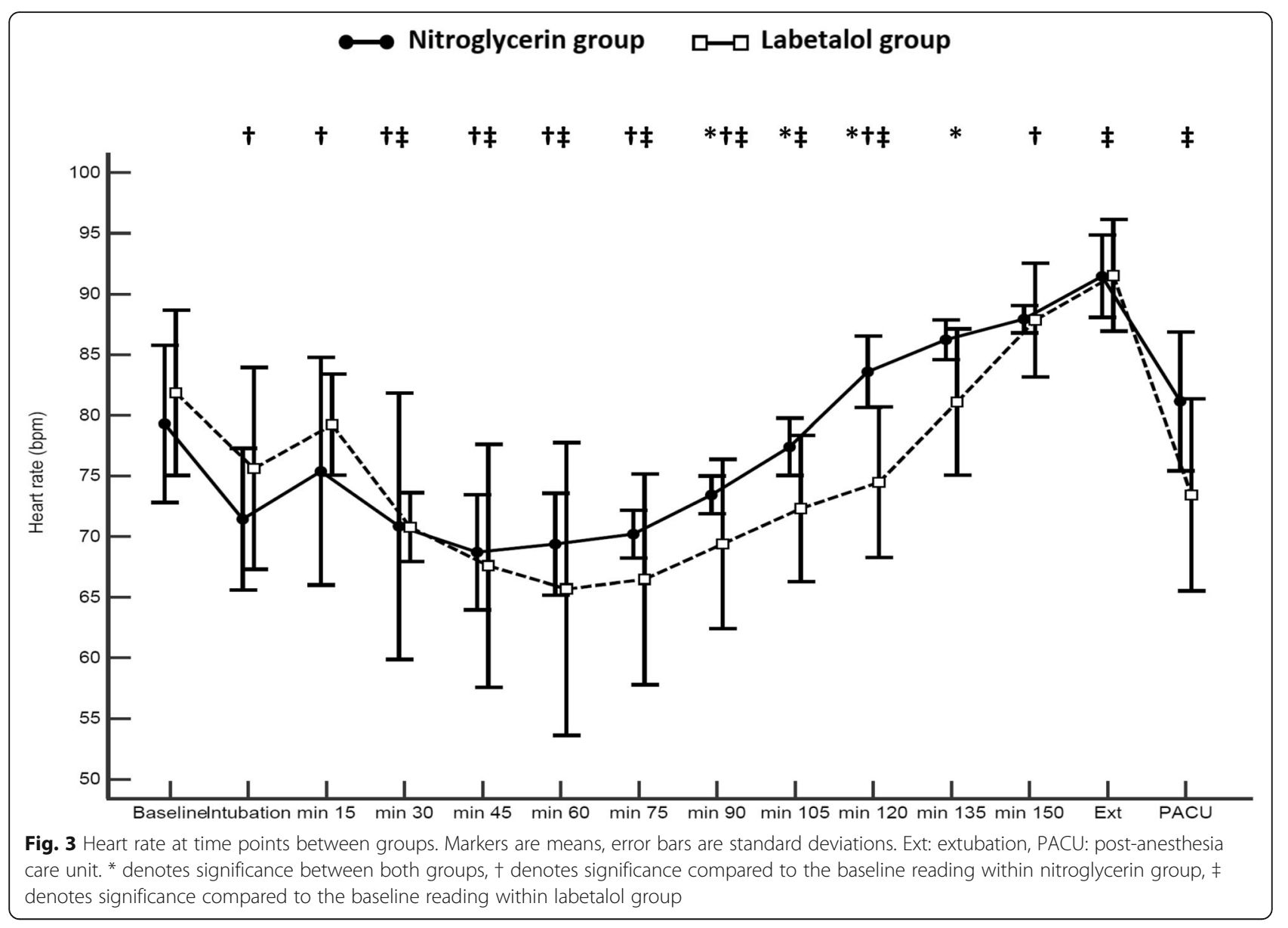

and microcirculatory recruitment [14]. On the other hand, Labetalol acts as an antagonist of $\alpha 1$ and $\beta$-adrenergic receptors at a ratio of $1: 7$ on intravenous administration; thus, it is considered to be a beta-blocker with some alpha-blocking activity [5, 8]. This explanation is supported by the positive effects of nitroglycerin infusion on microvascular flow in patients with septic shock $[12,13]$ and those with circulatory shock [14]. Furthermore, nitroglycerin-induced controlled hypotension was not associated with reduction in cerebral oxygen saturation or postoperative cognitive function [15].

We evaluated tissue perfusion using the oximetryderived PPI. PPI is characterized as a non-invasive, realtime measure that increases during vasodilatation [16], and decreases during sympathetic stimulation and impaired peripheral perfusion $[17,18]$. Moreover, parameters for evaluation of peripheral perfusion in the skin, including PPI, are increasingly being recommended as useful measures for body perfusion [19, 20]. PPI is used as an indicator of peripheral perfusion in intensive care units $[20,21]$ and operating theaters $[4,22]$. A recent study reported that monitoring PPI reflects changes in systemic hemodynamics during general anesthesia in a setting of changing preload conditions [4]. We used the
PPI for real-time monitoring of the peripheral perfusion while we measured the serum lactate at only two points because it is a slowly changing perfusion marker which is usually measured at 6-h intervals [3].

Nitroglycerin and labetalol were previously compared in achieving deliberate hypotension [6-9]. However, the results of previous studies did not totally favor one drug over the other. Our study revealed that SFS values were modestly lower in the labetalol group in the first $10 \mathrm{~min}$; however, the median SFS in the nitroglycerin group at 20 min was 2 (IQR 2-2.5), which is sufficient for good field quality. The subsequent SFS values were comparable in both groups until the end of the operation. In our patients, we found that the nitroglycerin group exhibited a higher heart rate in some intraoperative periods, while heart rate was comparable between the groups in most of the other readings. El-Shamma et al. and Hadavi et al. reported that nitroglycerin infusion was associated with more prominent reflex tachycardia compared with labetalol $[6,8]$. The difference between our results and those reported by ElShamma et al. and Hadavi et al. may be due to the higher dose of nitroglycerin or the larger sample sizes of their studies $[6,8]$. 


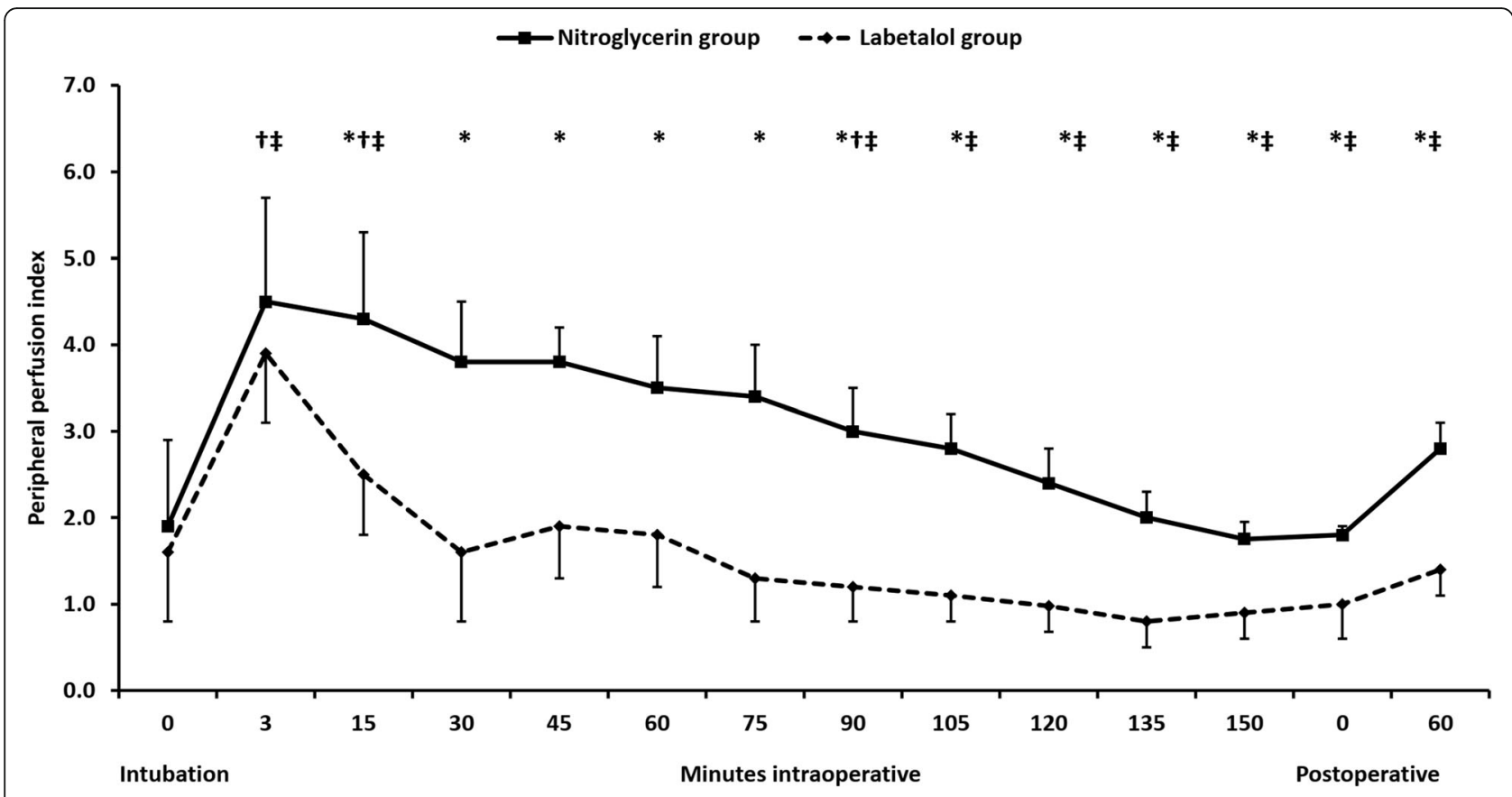

Fig. 4 Peripheral perfusion index. Markers are means, error bars are standard deviations. * denotes significance between both groups., $†$ denotes significance compared to the baseline reading within nitroglycerin group, $\neq$ denotes significance compared to the baseline reading within labetalol group

The "art" of hypotensive anesthesia is to achieve proper surgical conditions without suppressing perfusion of vital organs [1]. The risk for impairment of tissue perfusion has been the primary concern that limits the use of deliberate hypotension [23]. However, in our patients, we found that PPI did not decrease in the nitroglycerin group throughout the operation, despite the low blood pressure. Furthermore, serum lactate concentration was not significantly elevated in both groups. Therefore, we believe that deliberate hypotension should not be

Table 2 Outcomes measurements

\begin{tabular}{|c|c|c|c|}
\hline & Nitroglycerin group $(n=20)$ & Labetalol group $(n=20)$ & $P$ value \\
\hline Lactate pre-induction (mmol/L) & $0.4 \pm 0.1$ & $0.5 \pm 0.2$ & 0.261 \\
\hline Lactate post-operative (mmol/L) & $1.3 \pm 0.2$ & $1.7 \pm 0.4^{\mathrm{a}}$ & 0.001 \\
\hline Intra-operative Blood loss (ml) & $64 \pm 13.3$ & $57 \pm 9.3$ & 0.062 \\
\hline \multicolumn{4}{|l|}{ Surgical field score: } \\
\hline $10 \mathrm{~min}$ & $3(2.5-3)$ & $2(2-3)^{a}$ & 0.009 \\
\hline $20 \mathrm{~min}$ & $2(2-2.5)$ & $1.5(1-2)^{a}$ & 0.001 \\
\hline $30 \mathrm{~min}$ & $2(1-2)$ & $1(1-2)^{a}$ & 0.018 \\
\hline $40 \mathrm{~min}$ & $1(1-1)$ & $1(1-1)$ & 0.89 \\
\hline $50 \mathrm{~min}$ & $1(1-1)$ & $1(1-1)$ & 0.97 \\
\hline $60 \mathrm{~min}$ & $1(1-1)$ & $1(1-1)$ & 0.79 \\
\hline $70 \mathrm{~min}$ & $1(1-1)$ & $1(1-1)$ & 0.99 \\
\hline $80 \mathrm{~min}$ & $1(1-1)$ & $1(1-1)$ & 1 \\
\hline $90 \mathrm{~min}$ & $1(1-1)$ & $1(1-1)$ & 1 \\
\hline $100 \mathrm{~min}$ & $1(1-1)$ & $1(1-1)$ & 1 \\
\hline $110 \mathrm{~min}$ & $1(1-1)$ & $1(1-1)$ & 1 \\
\hline $120 \mathrm{~min}$ & $1(1-1)$ & $1(1-1)$ & 1 \\
\hline
\end{tabular}

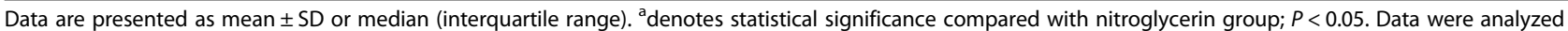
using the unpaired $t$ test and the analysis of variance for repeated measures as appropriate 
considered a state of circulatory shock. We assume that, under well-monitored peripheral perfusion, nitroglycerin could be a good choice to induce controlled hypotension if it is surgically indicated.

There were several limitations to our investigation, the first of which was that it was a single-center study. Second, we induced hypotension in only one type of surgery; thus, our findings with regard to surgical field may differ in other procedures. Third, our patients received the available drugs (i.e., isoflurane and fentanyl) in our hospital; the impact of study drugs in peripheral perfusion with other agents, such as sevoflurane and remifentanil, may require further research. Fourth, our findings are restricted to patients with no serious comorbidities. Finally, although we demonstrated that deliberate hypotension did not impair peripheral perfusion under the conditions of our study, more studies aimed at evaluating the effect of deliberate hypotension on the perfusion of vital organs are warranted.

\section{Conclusion}

Nitroglycerin-induced deliberate hypotension was accompanied by higher PPI and lower serum lactate levels compared with labetalol-induced deliberate hypotension during sinus endoscopic surgery.

\section{Abbreviations}

FESS: Functional Endoscopic Sinus surgery; MAP: Mean Arterial Pressure; PPI: Peripheral Perfusion Index; SFS: Surgical Field Score; ANOVA: Analysis Of Variance; Ext: Extubation; PACU: post-anesthesia care unit

\section{Acknowledgements}

We would like to thank Dr. Ahmed Mukhtar, professor of anesthesia, Cairo University, who helped in conception of the idea and whom no words could ever express his continued support and guidance.

\section{Authors' contributions}

MZ helped in conception of the idea, study design, acquisition of data, drafting and revising the manuscript. HN helped in study design, data analysis, drafting and writing the first manuscript. AH helped in study design, data analysis, and revising the manuscript. $\mathrm{PH}$ helped in conception of the idea and acquisition of data. DS, SM, GA, HE, EF, MI and NS helped in acquisition of data, and revising the manuscript. AHS in study design, data analysis and drafting the manuscript. All authors approved the manuscript and agreed to be accountable for all aspects of the work.

\section{Funding}

No external funding was used.

\section{Availability of data and materials}

Data are available from the authors upon reasonable request with permission from Cairo University.

\section{Ethics approval and consent to participate}

Research was performed in accordance with the Declaration of Helsinki. Ethical approval for this study was provided by our Institutional research ethics committee the Ethical Committee REC of kasralainy Hospitals, Cairo University with approval number (Ethical Committee Nº P-20170030606). Written informed consents were obtained from participants before inclusion.

\section{Consent for publication}

Not applicable.

\section{Competing interests}

The authors declare that they have no competing interests.

Received: 19 December 2019 Accepted: 12 April 2020

Published online: 17 April 2020

\section{References}

1. Erdem AF, Kayabasoglu G, Tas Tuna A, Palabiyik O, Tomak Y, Beyaz SG. Effect of controlled hypotension on regional cerebral oxygen saturation during rhinoplasty: a prospective study. J Clin Monit Comput. 2016;30: 655-60.

2. Lam AM. Controlled hypotension: completely forbidden or sometimes necessary? Eur J Anaesthesiol. 2000;17:93-5.

3. Hasanin A, Mukhtar A, Nassar H. Perfusion indices revisited. J Intensive Care. 2017:5:24.

4. Højlund J, Agerskov M, Clemmesen C, Edvardsen Hvolris L, Foss NB. The peripheral perfusion index tracks systemic haemodynamics during general anaesthesia. J Clin Monit Comput. 2019; [Epub ahead of print].

5. Richards DA, Prichard BN. Clinical pharmacology of labetalol. Br J Clin Pharmacol. 1979:8:895-93S

6. El-Shmaa NS, Ezz HAA, Younes A. The efficacy of labetalol versus nitroglycerin for induction of controlled hypotension during sinus endoscopic surgery. A prospective, double-blind and randomized study. J Clin Anesth. 2017;39:154-8.

7. Eltringham RJ, Young PN, Littlejohns PA, Robinson JM. A comparison of glyceryl trinitrate and labetalol as hypotensive agents in microsurgery of the middle ear. Eur Heart J. 1988;9(A):201-3.

8. Hadavi MR, Zarei Y, Tarogh S. Comparison of effects of labetalol and nitroglycerine on intraoperative blood loss and surgical field quality in rhinoplasty surgery. World J Plast Surg. 2015;4:60-5.

9. Ghodraty M, Khatibi A, Rokhtabnak F, Maleki M, Parsa F. Comparing labetalo and nitroglycerine on inducing controlled hypotension and intraoperative blood loss in Rhinoplasty: a single-blinded clinical trial. Anesthesiol Pain Med. 2017;7:e13677.

10. Fromme GA, MacKenzie RA, Gould AB, Lund BA, Offord KP. Controlled hypotension for orthognathic surgery. Anesth Analg. 1986;65:683-6.

11. Beurton A, Teboul J-L, Gavelli F, Gonzalez FA, Girotto V, Galarza L, et al. The effects of passive leg raising may be detected by the plethysmographic oxygen saturation signal in critically ill patients. Crit Care. 2019;23:19.

12. Corrêa TD, Filho RR, Assunção MSC, Silva E, Lima A. Vasodilators in septic shock resuscitation: a clinical perspective. Shock. 2017;47:269-75.

13. Spronk PE, Ince C, Gardien MJ, Mathura KR, Oudemans-van Straaten HM, Zandstra DF. Nitroglycerin in septic shock after intravascular volume resuscitation. Lancet. 2002;360:1395-6.

14. Lima A, van Genderen ME, van Bommel J, Klijn E, Jansem T, Bakker J. Nitroglycerin reverts clinical manifestations of poor peripheral perfusion in patients with circulatory shock. Crit Care. 2014;18:R126.

15. Choi SH, Lee SJ, Jung Y-S, Shin Y-S, Jun DB, Hwang KH, et al. Nitroglycerin- and Nicardipine-induced hypotension does not affect cerebral oxygen saturation and postoperative cognitive function in patients undergoing Orthognathic surgery. J Oral Maxillofac Surg. 2008; 66:2104-9.

16. Abdelnasser A, Abdelhamid B, Elsonbaty A, Hasanin A, Rady A. Predicting successful supraclavicular brachial plexus block using pulse oximeter perfusion index. Br J Anaesth. 2017;119:276-80.

17. Hasanin A, Mohamed SAR, El-adawy A. Evaluation of perfusion index as a tool for pain assessment in critically ill patients. J Clin Monit Comput. 2017; 31:961-5.

18. Rasmy I, Mohamed H, Nabil N, Abdalah S, Hasanin A, Eladawy A, et al. Evaluation of perfusion index as a predictor of vasopressor requirement in patients with severe sepsis. Shock. 2015;44:554-9.

19. Hariri G, Joffre J, Leblanc G, Bonsey M, Lavillegrand J-R, Urbina T, et al. Narrative review: clinical assessment of peripheral tissue perfusion in septic shock. Ann Intensive Care. 2019;9:37.

20. Lotfy A, Hasanin A, Rashad M, Mostafa M, Saad D, Mahmoud M, et al. J Clin Monit Comput. 2020. https://doi.org/10.1007/s10877-020-00483-1 [Epub ahead of print].

21. Sivaprasath P, Mookka Gounder R, Mythili B. Prediction of shock by peripheral perfusion index. Indian J Pediatr. 2019;86(10):903-8. 
22. Tapar H, Karaman S, Dogru S, Karaman T, Sahin A, Tapar GG, et al. The effect of patient positions on perfusion index. BMC Anesthesiol. 2018;18:111.

23. Jiang J, Zhou R, Li B, Xue F. Is deliberate hypotension a safe technique for orthopedic surgery?: a systematic review and meta-analysis of parallel randomized controlled trials. J Orthop Surg Res. 2019;14:409.

\section{Publisher's Note}

Springer Nature remains neutral with regard to jurisdictional claims in published maps and institutional affiliations.

Ready to submit your research? Choose BMC and benefit from:

- fast, convenient online submission

- thorough peer review by experienced researchers in your field

- rapid publication on acceptance

- support for research data, including large and complex data types

- gold Open Access which fosters wider collaboration and increased citations

- maximum visibility for your research: over $100 \mathrm{M}$ website views per year

At $B M C$, research is always in progress.

Learn more biomedcentral.com/submissions 